\title{
Modification of DOHEAT for Optimization of Coolant Conditions in DEMO Blanket ${ }^{*}$
}

\author{
Hiroyasu UTOH, Kenji TOBITA, Youji SOMEYA and Makoto NAKAMURA \\ Japan Atomic Energy Agency, Rokkasho-mura, Aomori 039-3212, Japan
}

(Received 9 December 2011 / Accepted 1 May 2012)

\begin{abstract}
For optimization of coolant conditions in DEMO blanket design, a two-dimensional (2D) nuclear-thermalcoupled analysis code, DOHEAT, has been modified. A striking feature of DOHEAT is to have a user-friendly interface that enables users to create an appropriate analysis model for different blanket concepts without much diffculty. In the modified DOHEAT, the coolant condition calculation module was added into the 2D thermal analysis module, and the temperature profile in the blanket was provided based on the nuclear heating rate profile and coolant temperature. In addition, numerical solution of simultaneous linear equation is changed from successive over relaxation (SOR) method to bi-conjugate gradient stabilized (Bi-CGStab) method for calculation speed-up. By improving DOHEAT, a series of blanket analysis including not only neutronics and thermal analysis but also coolant condition can be done. The modified DOHEAT allows to calculate the temperature change of the coolant along the cooling tube, and to evaluate the accurate temperature distribution of blanket.
\end{abstract}

(C) 2012 The Japan Society of Plasma Science and Nuclear Fusion Research

Keywords: blanket, design, fusion reactor, nuclear analysis, coolant, thermal analysis, DOT3.5

DOI: $10.1585 /$ prr.7.2405109

\section{Introduction}

In a fusion reactor, the blanket performs important functions of (1) tritium breeding, (2) heat production, and (3) radiation shielding. In particular, self-sufficient supply of tritium is one of the most important requirements for a fusion power reactor. Therefore, reliable neutronics calculations based on a detailed model are necessary to ensure the tritium self-sufficiency, and thus it would be favorable to carry out three-dimensional (3D) calculations adopting 3D Monte Carlo N-particle transport code MCNP [1] at the final stage of design work as ITER-TBM [2,3]. On the other hands, in the early design stage, one is requested to find a possible best solution considering all possible breeding materials, coolants and the interior arrangements. In such a case, neutronics analysis on a 3D basis is less efficient. Instead, lower dimensional (1D or 2D) analysis will show efficient performance because such an analysis significantly saves the time required for preparing a large number of calculation models and for completing the calculations.

Because of the background, a one- dimensional (1D) analysis code, ANIHEAT has been developed in JAEA. ANIHEAT is a nuclear-thermal -coupled analysis code for blanket analysis. In ANIHEAT, neutron and gamma flux are calculated by the 1D transport code, ANISN [4], and the nuclear heating rate and TBR are estimated using a neutronics calculation code, APPLE-3 [5]. Although ANIHEAT allows 1D analysis which approximates all blanket

author's e-mail: uto.hiroyasu@jaea.go.jp

*) This article is based on the presentation at the 21st International Toki Conference (ITC21). components by a multi-layered slab model, it is useful for a sort of blanket design having multi-layered structure in the radial direction like DEMO-2001 [6]. However, application of such a 1D analysis is not always applicable to blanket design. For example, for a blanket in which breeder or multiplier is arranged in the toroidal direction like a Helium Cooled Pebble Bed (HCPB) blanket concept of PPCS model B [7], a modeling based on "slab" is no more appropriate.

For evaluation of the realistic blanket model, we have developed a completely new 2D blanket design code "DOHEAT" [8] coupling neutronics and heat transport. DOHEAT has user-friendly interfaces that construct various complex blanket analysis model structures. However, in the previous version of DOHEAT, the coolant temperature is given as an input data. Actually, a temperature change of the coolant along the cooling tube needs to be determined implicitly when the inlet temperature, pressure and flow speed are given. Additionally, the coolant conditions are the parameters that have effect not only on blanket design, but also system design including power generation system. In order to evaluate the accurate temperature of blanket and the coolant conditions, DOHEAT has been modified. This paper describes a modified 2D blanket analysis code DOHEAT.

\section{The DOHEAT Code \\ 2.1 Outline of the code}

The analysis part of DOHEAT is divided into three; One is the $2 \mathrm{D} \mathrm{S}_{\mathrm{N}}$ transport module, DOT3.5 [9], neutronics 


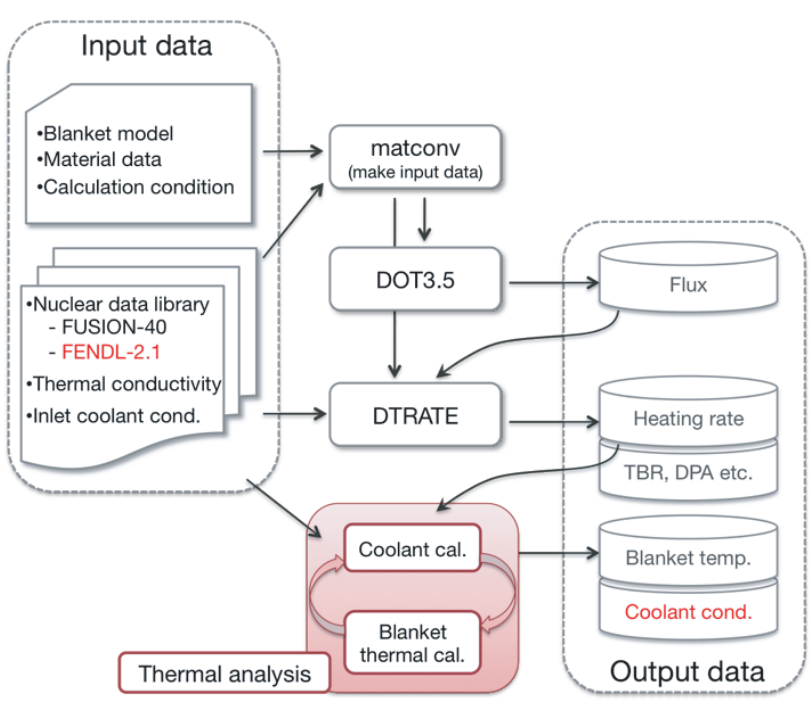

Fig. 1 Structure of modified DOHEAT code.

calculation code, the second is DTRATE based on APPLE3 , and the third is $2 \mathrm{D}$ thermal analysis code. Figure 1 shows the structure of modified DOHEAT code. A user can select the nuclear data libraries FUSION-40 [10] based on JENDL-3.1 [11] or FENDL-2.1 [12]. In the modified DOHEAT, a coolant loop analysis code is added for calculation of coolant conditions. The temperature distribution of blanket is obtained after several iterations between coolant loop calculation and 2D steady-state heat transfer calculation. Therefore, the numerical solution of simultaneous linear equation is changed from successive over relaxation (SOR) method to bi-conjugate gradient stabilized (Bi-CGStab) method [13] for calculation speed-up.

\subsection{Modified thermal analysis code}

\subsection{1 coolant loop analysis}

The coolant conditions such as coolant temperature, pressure and velocity are determined by heat balance between heat source and heat removal by coolant, as shown as the following equation.

$$
\int \dot{q} \mathrm{~d} V=S \int_{\Delta T} v(T, p) \rho(T, p) C_{\mathrm{p}}(T, p) \mathrm{d} T .
$$

Where, $\dot{q}$ is heat source $\left(\mathrm{W} / \mathrm{m}^{3}\right), S$ is cross-section area of coolant $\left(\mathrm{m}^{2}\right), v$ is coolant velocity $(\mathrm{m} / \mathrm{s}), \rho$ is density of coolant $\left(\mathrm{kg} / \mathrm{m}^{3}\right), C_{\mathrm{p}}$ is constant pressure specific heat $(\mathrm{J} / \mathrm{kgK}), p$ is coolant pressure and $\Delta T$ is temperature change of coolant. The boundary of heat source removed by the coolant is decided from heat flow direction calculated by thermal analysis (Fig. 2). The analysis model of coolant loop is made in a "modeling space" in the upper part of nuclear and thermal analysis model using built-in basic objects such as elbow, header, etc. The user can select a kind of header, inlet header, outlet header and branch header. In the case of branch header, the number of branches is entered manually into the code. The follow-

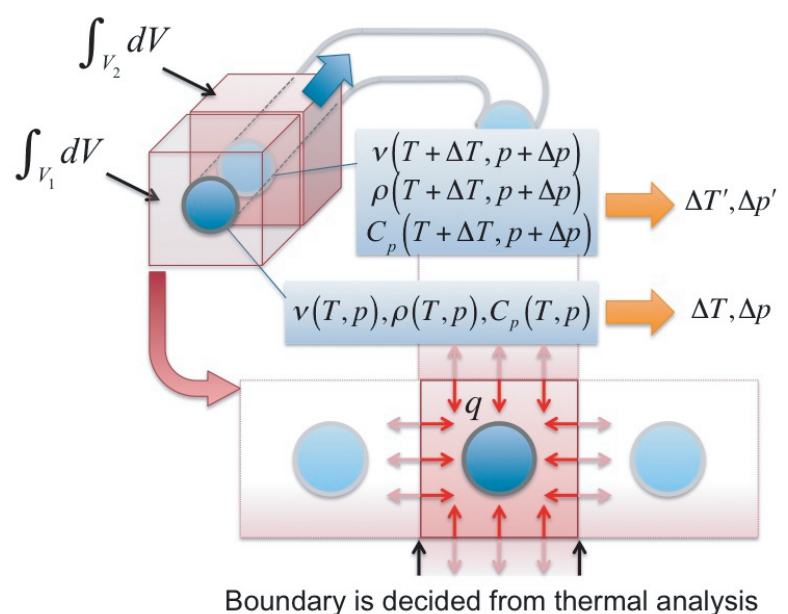

Fig. 2 Coolant loop analysis model.

ing parameters are input for coolant analysis code.

- Coolant: Water or He gas

- Blanket module size

- Inlet temperature $\left({ }^{\circ} \mathrm{C}\right)$

- Inlet pressure (MPa)

- Inlet velocity $(\mathrm{m} / \mathrm{s})$

- Header size

\subsection{2 pressure drop}

Pressure drop is determined by the Darcy-Weisbach formula, as shown in the following;

$$
\Delta p=\varsigma \rho v^{2} / 2
$$

Here, $\Delta p$ is pressure drop $(\mathrm{Pa}), \rho$ is density of coolant $\left(\mathrm{kg} / \mathrm{m}^{3}\right), v$ is coolant velocity $(\mathrm{m} / \mathrm{s})$ and $\zeta$ is loss coefficient. In DOHEAT, $\zeta$ is determined by the kind of coolant tube as the following, respectively.

- Straight tube

$$
\varsigma=\lambda l / d
$$

Here, $\lambda$ is friction factor, $l$ is flow path length and $d$ is inner diameter of coolant tube.

- Elbow $\left(90^{\circ}\right)$

$$
\varsigma=1.265 \text {. }
$$

· Header (in): Enlargement

$$
\varsigma=\left(\frac{A_{2}}{A_{1}}-1\right)^{2} \text {. }
$$

Here, $A_{1}$ is cross-section area of upper flow and $A_{2}$ is crosssection area of lower flow.

- Header (out): Contraction

$$
\varsigma=\left(1-\frac{A_{1}}{A_{2}}\right)^{2} \text {. }
$$

Here, $A_{1}$ is cross-section area of upper flow and $A_{2}$ is crosssection area of lower flow. 


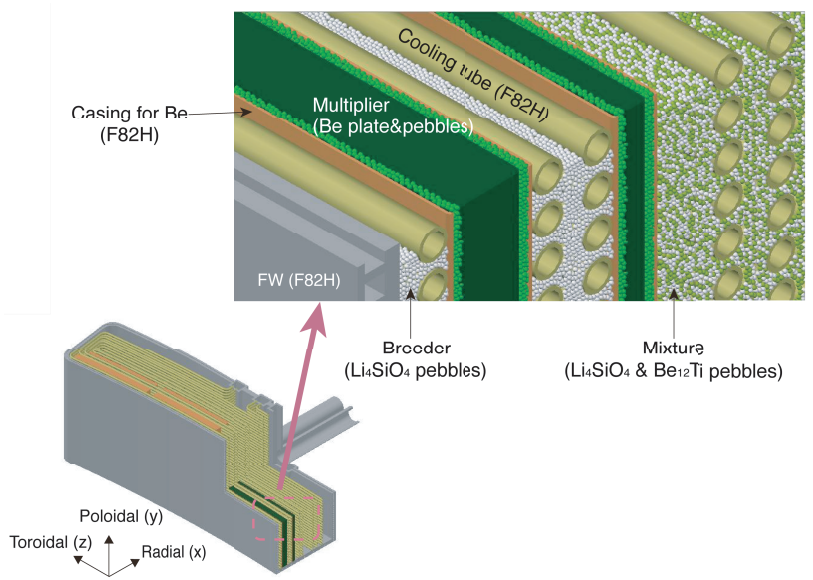

Fig. 3 Concept of blanket interior in SlimCS [14].

* Coolant loop model

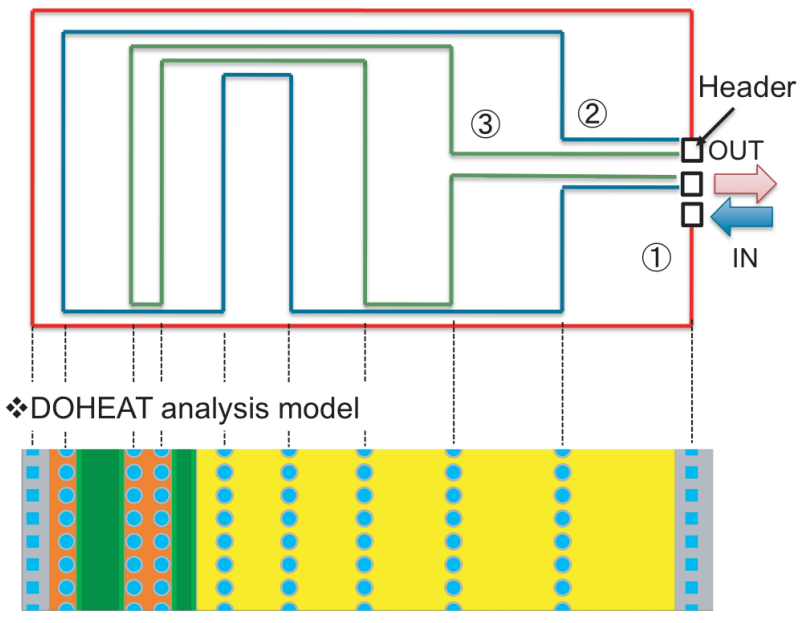

Fig. 4 Analysis model of coolant loop arrangement and blanket interior arrangement in DOHEAT.

\section{Calculation Results}

\subsection{Coolant loop analysis of a SlimCS-like blanket model}

The analysis model for a SlimCS-like blanket $[14,15]$ is shown in Fig. 3. The ceramic breeder pebble bed $\mathrm{Li}_{4} \mathrm{SiO}_{4}$ and the multiplier pebble bed Beryllium (Be) and Be block were separated by cooling tubes and partitions made of $\mathrm{F} 82 \mathrm{H}$. In the back ward zones, $\mathrm{Be}_{12} \mathrm{Ti}$ is adopted as a multiplier. The width of the blanket model is $450 \mathrm{~mm}$ in radial direction, the length is $2000 \mathrm{~mm}$ in toroidal direction, and $600 \mathrm{~mm}$ in poloidal direction. The coolant was subcritical water $\left(23 \mathrm{MPa}, 290^{\circ} \mathrm{C}\right)$, and cooling channel in the first wall is $8 \times 8 \mathrm{~mm}$, cooling pipe diameter is $12 \mathrm{~mm}$ and the pipe bore is $9 \mathrm{~mm}$. The inlet velocity is $5.3 \mathrm{~m} / \mathrm{s}$. The neutron wall load on first wall was $5 \mathrm{MW} / \mathrm{m}^{2}$, and the surface heat flux on first wall was $1 \mathrm{MW} / \mathrm{m}^{2}$. Figure 4 shows analysis model of coolant loop arrangement and blanket interior arrangement in DOHEAT. The coolant from the FW channel into the header would be divided into two branches to supply the two piping circuits. The to-
Table 1 Comparison between total quantity of heat from nuclear analysis and coolant analysis.

\begin{tabular}{lccc}
\hline & $\begin{array}{c}\text { Heating rate } \\
\text { from nuclear } \\
\text { analysis }\end{array}$ & $\begin{array}{c}\text { Coolant } \\
\text { received }\end{array}$ & $\begin{array}{c}\text { Spec. } \\
\text { enthalpy } \times \\
\text { flow }\end{array}$ \\
\hline $\begin{array}{l}\text { Total Q } \\
(\mathrm{MW})\end{array}$ & 0.1738 & 0.1738 & 0.1743 \\
$\begin{array}{l}\text { Relative } \\
\text { error }(-)\end{array}$ & - & $-7.0 \times 10^{-8}$ & $2.9 \times 10^{-3}$ \\
\hline
\end{tabular}

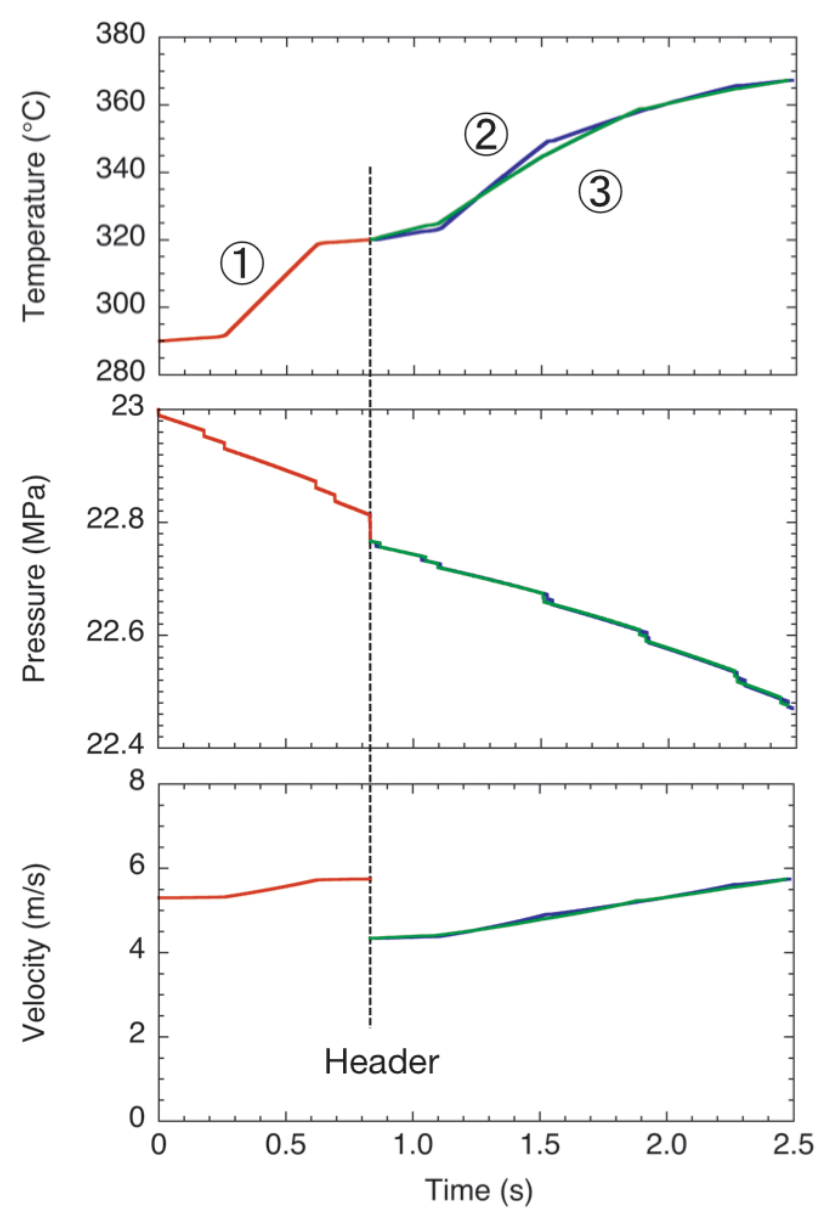

Fig. 5 Time evolutions of coolant temperature, pressure and velocity.

tal quantity of nuclear heating rate calculated by DTRATE and total quantity of heat removed by coolant has received are shown in Table 1. A reasonable agreement is seen between total heat quantity from nuclear analysis and coolant analysis. Figure 5 shows the time evolution of coolant temperature, pressure and velocity. As shown in this figure, the temperature, pressure and velocity change of the coolant along the cooling tube ware accurately-assessed.

\subsection{Thermal analysis in modified DOHEAT}

In the modified DOHEAT, the numerical solution of simultaneous linear equation is changed from SOR method 
Table 2 Calculation time per one thermal analysis in SOR method and Bi-CGStab method.

\begin{tabular}{lcc}
\hline & SOR method & $\begin{array}{c}\text { Bi-CGStab } \\
\text { method }\end{array}$ \\
\hline $\begin{array}{l}\text { Calculation } \\
\text { time (sec.) }\end{array}$ & 1893 & 0.1743 \\
$\begin{array}{l}\text { Max. relative } \\
\text { error }(\%)\end{array}$ & - & $2.9 \times 10^{-3}$ \\
\hline
\end{tabular}

(a)
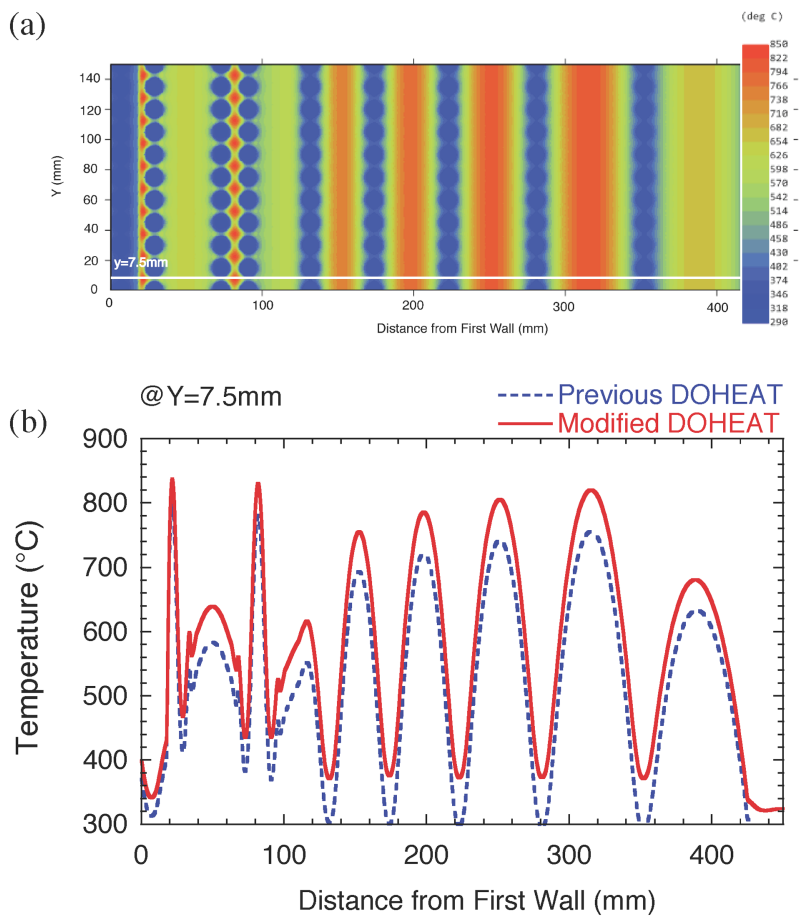

Fig. 6 (a) 2D temperature distribution after coolant temperature iteration from modified DOHEAT and (b) the temperature distribution from previous DOHEAT and modified DOHEAT at $y=7.5 \mathrm{~mm}$.

to Bi-CGStab method for calculation speed-up. Table 2 shows the calculation time per one thermal analysis in previous DOHEAT (SOR method) and modified DOHEAT (Bi-CGStab method). By replacing SOR with Bi-CGStab, the calculation time reduced dramatically. Figure 6 shows (a) the $2 \mathrm{D}$ temperature distribution after coolant temperature iteration from modified DOHEAT and (b) the temperature distribution from previous DOHEAT and modified DOHEAT at $y=7.5 \mathrm{~mm}$. Blue dotted line is previous DOHEAT and red line is modified one. In this case, thermal analysis iteration in modified DOHEAT was 4 times. The temperature obtained by previous DOHEAT was underes- timated about $60^{\circ} \mathrm{C}$. By improving DOHEAT, the accurate thermal analysis can be done. The temperature in excess of operation temperature of blanket components requires an increase in cooling channel, that is, a decrease in TBR. The difference of temperature is caused by the difference of analysis model, suggesting the importance of the thermal analysis including coolant temperature for reasonable TBR assessment.

\section{Conclusion}

For optimization of coolant conditions in DEMO blanket design, a two-dimensional (2-D) blanket analysis code, DOHEAT, has been modified. A remarkable feature of the code is a user-friendly graphical interface which allows to prepare an appropriate analysis model of a variety of blanket concepts with different materials in a short time. The modifications DOHEAT are as follows; 1) add new coolant loop analysis code and 2) modified SOR method to Bi-CGStab method. By improving DOHEAT, a series of blanket analysis including not only neutronics and thermal analysis but also coolant condition can be done. Au underestimation of temperature distribution leads to an overestimation of TBR. The modified DOHEAT allows to calculate the temperature change of the coolant along the cooling tube, and to evaluate the accurate temperature distribution of blanket.

\section{Acknowledgments}

This work was partly supported by the BA DEMO Design Activity.

[1] X-5 Monte Carlo Team, MCNP-A General Monte Carlo NParticle Transport Code, Version 5, Vol. II, La-CP-03-0245, Los Alamos National Laboratory, 2003.

[2] D. Aquaro et al., Fusion Eng. Des. 82, 2226 (2007).

[3] M.E. Sawan et al., Fusion Eng. Des. 85, 1027 (2010).

[4] W.W. Eng1e, K-1693, Union Carbide Corporation, Computing Technology Center (1967).

[5] H. Kawasaki, JAERI-M91-058 (1991).

[6] M. Enoeda et al., Nucl. Fusion 43, 1837 (2003).

[7] PPCS overall report (2004).

[8] H. Utoh et al., Fusion Eng. Des. 86, 2378 (2011).

[9] W.A. Rhoades and F.R. Mynatt, ORNL/RSIC/CCC-276 (1975).

[10] K. Maki et al., JAERI-M91-072 (1991).

[11] K. Shibata et al., JAERI 1319 (1990).

[12] D.L. Aldama and A. Trkov, INDC(NDS)-467, IAEA (2004).

[13] H.A. van der Vorst, J. Sci. Stat. Comput. 13, 631 (1992).

[14] K. Tobita et al., Fusion Eng. Des. 85, 1342 (2010).

[15] C. Liu et al., Fusion Eng. Des. 85, 979 (2010). 